\title{
Newly expanded European Union faces growing pains
}

New members of the expanded European Union (EU) could boost the profile of biomedical research in the region by providing fertile breeding ground for low-cost clinical research. At the same time, they could see their best brains leave for even more fertile soil abroad.

On 1 May, nearly 75 million Eastern and Central Europeans became citizens of what used to be called Western Europe. Together with the islands of Cyprus and Malta, the formerly communist states of Latvia, Estonia, Lithuania, Poland, the Czech Republic, Slovakia, Slovenia and Hungary formally joined the EU, shifting its geographical heart 340 kilometers to the east. Bulgaria and Romania are expected to follow in three years.

In many ways, the expanded EU seems farther removed from its goal of becoming a center of science and innovation. In 2001, eight of the ten new members spent less than $1 \%$ of their gross domestic product on research and development, compared with the $3 \%$ spending level the EU foresees for 2010. With 25 different governments to appease, controversial decisions - such as guidelines for cloning and the reform of the European research funding process-will only become more difficult.

In some new member countries, there are concerns that health care costs will skyrocket because many cheap generic drugs formerly imported from Russia or Ukraine won't pass muster in the EU. Others worry about a potential 'brain drain' to the west.

Schemes designed to promote 'brain circulation' within the EU, such as the Marie Curie

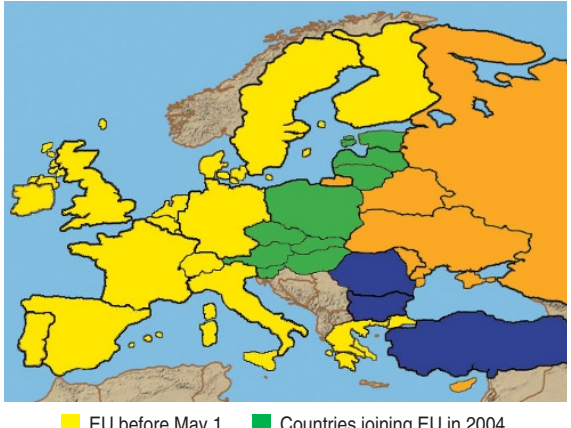

EU before May $1 \quad$ Countries joining EU in 2004

Work Programme, might amplify existing inequalities between member states, says Louise Ackers of the University of Leeds.

Countries with a strong research infrastructure, better labs and higher levels of funding, lure and retain talented researchers. In the 'old' EU the UK, Germany and France were big winners. Unable - or unwilling - to compete with the richer members, Italy, Spain and Greece led the charts on the losing side.

The same could happen with the new members, particularly as many in the EU argue that research funding should focus more on scientific excellence and less on geographical fairness, says Ackers. Polls among undergraduates in eastern and central Europe show that many of them consider leaving-one Bulgarian survey found that $70 \%$ of its students had considered emigrating.

Others are more optimistic. István Raskó, director of the Institute of Genetics in Szeged, Hungary, says young Hungarian researchers' emigration is balanced by incoming students from Nordic countries. Still, he says, the new members should prioritize incentives to entice researchers working abroad to return.

Raskó is concerned that he and others will have to compete for EU funds on equal terms with established research centers elsewhere. Although eastern labs deliver high-quality research, he says, "research productivity is the key to getting new grants, and it is lower here than in countries with much better facilities."

At least one research area could see strong growth, says Roy Lenders, lead author of a recent report on EU enlargement. Low costs and large pools of research subjects could set the stage for a clinical trials boom in the EU, particularly once patent regulations are harmonized.

Wages and investigator grants are low in most new member states, but the research quality is at least as high as it is elsewhere in Europe, Lender says. Compared with western Europe, regulation in eastern and central Europe is also still manageable. Limited access to affordable health care makes the population more willing to participate in trials, and because most former communist states have large hospitals, recruiting patients is quick and easy.

Some of these advantages might dissolve as the member states develop, Lenders says, but that is not likely to happen within the 5- to 10year investment horizon of drug companies. "Countries like Greece and Spain joined the EU in the 1980s," he says, "but their salaries are still lower than elsewhere."

Peter Vermij, Amsterdam

\section{Biomedical research budget comes up short down under}

Australian biomedical researchers walked away disappointed from this year's federal government budget, amidst concerns that the nation's biomedical research will struggle to keep pace with the international community.

The budget, released on 11 May, forecasts that annual funds for the National Health and Medical Research Council (NHMRC) - the primary funding agency for biomedical research—will remain steady at nearly AUS $\$ 400$ million.

This falls far short of the extra AUS $\$ 1$ billion over five years that medical research lobby groups argue is needed to maintain Australia's current level of research. "It has come as a great surprise-it's even more surprising given there is such large surplus left," says Andrew Sinclair, president of the Australian Society for Medical Research. There had been earlier political support for medical and health research and a growing emphasis on care for the aged.

Many researchers fear a widening gap between funding and the escalating costs of medical research. "Our costs of grants have far outstripped inflation," says Alan Pettigrew, chief executive officer of the NHMRC.

On 6 May, the federal government announced some urgently needed funds for the infrastructure of medical institutes, which are currently supported by state governments. Those institutes will have AUS $\$ 200$ million over seven years-allocated in proportion to their competitive grant awards - available to them, as well as AUS $\$ 31.2$ million for specific infrastructure projects.

The Commonwealth Scientific and Industrial Research Organisation (CSIRO), the nation's largest research body, will receive an additional AUS\$305 million dollars over seven years for its six priority-driven programs.

But baseline funding for CSIRO and the Australian Research Council, which funds basic research, will remain relatively constant, with only modest increases over the next few years. "If we go flat-line now that means we'll start slipping back - there is no question of that," says Sinclair.

Researchers are clinging to the hope that additional funds are waiting in the wings. The government has yet to release a muchanticipated review commissioned to assess investment into the medical and health research sector. Observers say the government might use promises of extra funding as a platform in the federal elections later this year.

Carina Dennis, Sydney 